Case Report

\title{
Cerebral Falx Mature Teratoma with Rare Imaging in an Adult
}

\author{
Jingwei Zhao ${ }^{{ }^{*}}$, Haifeng Wang ${ }^{1^{*}}$, Jing $\mathrm{Yu}^{2}$, Yanping Zhong ${ }^{3}$, Pengfei $\mathrm{Ge}^{1 凶}$
}

1. Department of Neurosurgery, First Bethune Hospital of Jilin University, Changchun 130021, Jilin Province, P.R. China.

2. Department of Operation Room, First Bethune Hospital of Jilin University, Changchun 130021, Jilin Province, P.R. China.

3. Department of Pathology, First Bethune Hospital of Jilin University, Changchun 130021, Jilin Province, P.R. China.

* Jingwei Zhao and Haifeng Wang contributed equally to this paper.

Corresponding author: Pengfei Ge, Department of Neurosurgery, 1st Bethune Hospital, Jilin University.71 xinmin Avenue, Changchun 130021, Jilin Province, P.R. China. E-mail: pengfeige@gmail.com.

(c) Ivyspring International Publisher. This is an open-access article distributed under the terms of the Creative Commons License (http://creativecommons.org/ licenses/by-nc-nd/3.0/). Reproduction is permitted for personal, noncommercial use, provided that the article is in whole, unmodified, and properly cited.

Received: 2012.01.03; Accepted: 2012.05.01; Published: 2012.05.24

\begin{abstract}
Intracranial mature teratoma is a rare lesion in adults. Despite several intracranial mature teratomas had been reported not to be located at the midline region, no one was found to be within cerebral falx. Herein, we reported a 37 -year-old female patient with an intracranial mature teratoma confined within frontal cerebral falx. Her main complaint was intermitted headache, which could not be relieved recently by taking painkiller. Excepting for mild papilledema, we did not find positive neurological signs on physical examination. CT scanning showed it was a round homogenously hypodense lesion with hyperdense signal at its rim. MRI revealed the lesion was $3.5 \mathrm{~cm} \times 3.6 \mathrm{~cm} \times 4.5 \mathrm{~cm}$ in volume, with uniformed hypointensity on TIWI, hyperintensity on $\mathrm{T} 2 \mathrm{WI}$ and enhancement in the capsule. It was totally removed via inter-hemispheric approach, and we found the lesion was confined within the frontal cerebral falx. Postoperatively, it was proved histologically to be a mature teratoma. At three years of fellow up, neither neurological deficits nor recurrent sings on MRI was found. To our best knowledge, this is the first case of intracranial mature teratoma within cerebral falx.
\end{abstract}

Key words: Mature teratoma; Dura mater; Cerebral falx; Adults.

\section{Introduction}

Intracranial teratomas are rare congenital disease, accounting for only about $0.5 \%$ of all intracranial tumors [1]. They are believed to originate from the abnormal distribution of germ cells during the 3rd to 5 th weeks of gestation. The components within them could derive from three germ layers, the ectoderm, mesoderm and endoderm [2]. Pathologically, teratomas are classified pathologically into mature, immature and malignant types. Mature teratomas are composed of well-differentiated elements, whereas immature teratomas contain components resembling fetal tissues [3, 4].

The natural history of intracranial teratomas is still incomplete understood partly due to its low incidence. Recent finding showed that intracranial ter- atomas display a degree of progressive disorganized growth and are capable of invading adjacent normal tissue as a result of their increasing size [5].

Within cranium, despite mature teratomas are often located at the midline regions including the sella region, corpus callosum, and cerebellar vermis [6-8]. However, intracranial mature teratomas were also found to be located at non-midline regions, including cerebellar hemisphere, basal ganglia, lateral ventricle, fourth ventricle, Sylvian fissure, cavernous sinus, sella, and the temporal bone [9-11].

Radiographically, mature teratomas often display heterogeneous densities on CT imaging due to containing different well-differentiated components such as soft tissue, cartilage or bone. On MR imaging, 
they also have a pattern of mixed signal intensity and various degree of enhancement [10-12]. In addition, calcification can be found in half cases of mature teratomas, occasionally with mature bone or teeth, so that it was proposed that mature teratomas might be suspected by the presence of midline or paraxial calcifications [12]. Preoperatively, intracranial dermoid cysts, lipoma craniopharyngioma should be listed as differential diagnosis items. Particularly, it should be emphasized to differentiate mature teratoma from epidermoid cyst on neuro-imaging, because epidermoid could be located at midline-regions $[13,14]$ and teratoma could also showed the imaging features as epidermoid cyst did [8].

In this report, we described an adult female with a mature teratoma confined within the frontal cerebral falx, which showed imaging different with previous description. In combination with literature review, we discussed the pathogenesis, imaging features and treatment of intracranial teratomas.

\section{Case report}

A 37-year-old female patient was admitted for intermitted headache of 6-year duration. She used to take painkiller (Aspirin or Ibuprofen Sustained-Release Capsules) to relieve the headache, but recently it had not been effective as before. On physical examination, except for mild papilledema, no positive neurological signs were found. Head CT scanning revealed a round lesion between two frontal lobes, with homogenous hypo-density containing a small region of hyper-density in its rim (Fig. 1 A). On MRI, the lesion was $3.5 \mathrm{~cm} \times 3.6 \mathrm{~cm} \times 4.5 \mathrm{~cm}$ in volume and located above the corpus callosum and between the both frontal lobes. It displayed uniformed hypo-intensity on T1WI and hyperintensity on T2WI, with capsule enhancement on contrast images (Fig. 1 B, C and D). During surgery, left frontal craniotomy was performed and inter-hemispheric approach was used to reach the lesion. The lesion was enveloped by a thick white capsule, which was subsequently proved to be a part of the cerebral falx. We firstly cut the capsule at the top end and evacuated its soft, yellowish and greasy content, and then its capsule and the involved dura mater were totally removed. In the capsule wall, a little piece of bone-like material was found (Fig. 1 E). Patho-histological examination of the removed tissues demonstrated the lesion contained well differentiated adipose tissue, mature bone and keratin-producing squamous epithelium (Fig. $1 \mathrm{~F}$ and G), which were consistent with the diagnosis criteria of a mature teratoma. Postoperatively, the patient recovered uneventfully and was discharged one week later. At three years of follow-up, neither neurological deficits nor recurrence signs was found (Fig 2 A, B and $\mathrm{C})$.

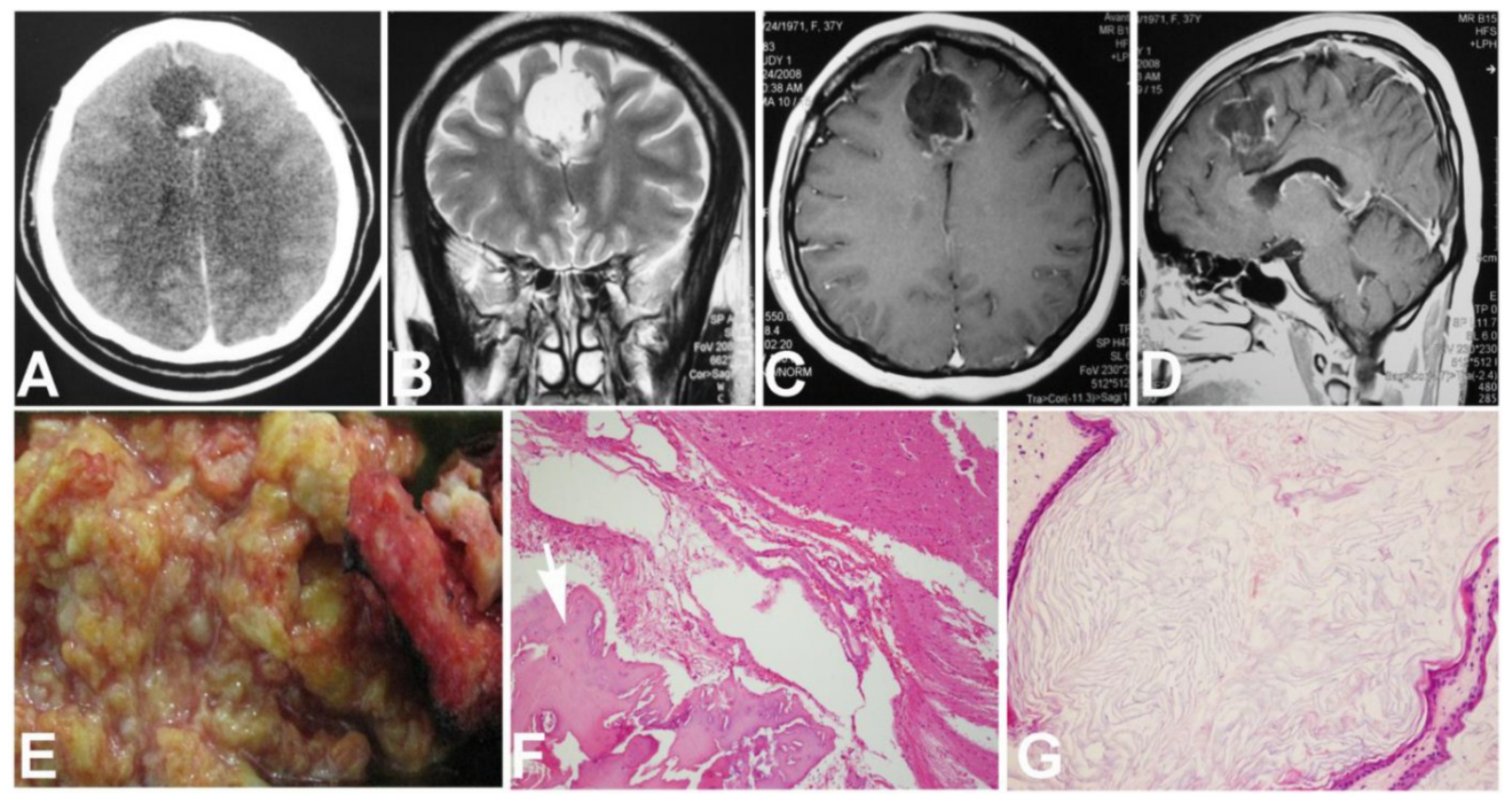

Figure I. Preoperative CT, MRI and histological images. A. CT scanning showed a round homogenously hypodense lesion with hyperdense signal in the wall. B. Coronal T2 weighted image showed a well-defined homogeneously hyperintense lesion with no surrounding edema. C. Axial TI contrast weighted image showed enhancement in the capsule. D. The gross appearance of the removed tissue. E. Microscopic image showed bone tissue (arrow head, hematoxylin \& eosin, $\times 10$ ). F. Epithelia with keratin under microscope (hematoxylin \& eosin, $\times 20$ ). 

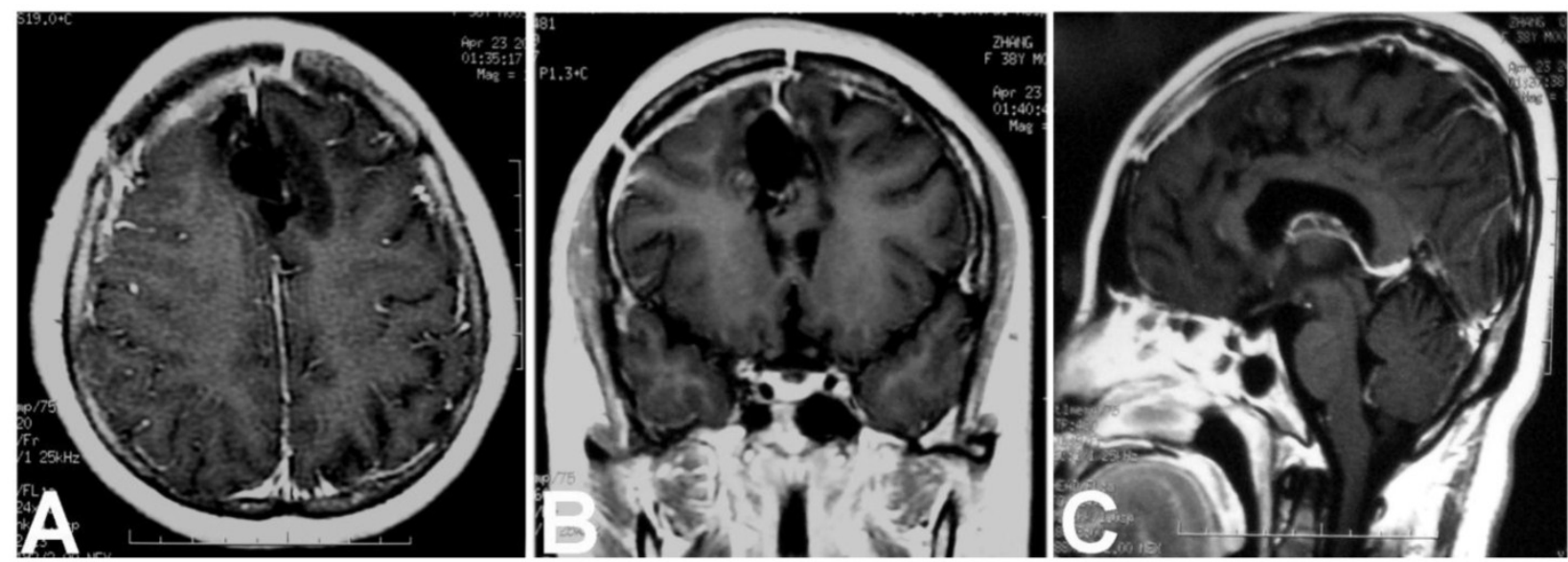

Figure 2. Postoperative enhanced MRI showed no residual or recurrence of the teratoma at three years of fellow up. A. Axial image; B. Coronal image; C. Sagittal image.

Table I. Summary of intracranial dural mater based mature teratomas in adult patients in recent 10 years.

\begin{tabular}{|c|c|c|c|c|c|}
\hline & Age/Sex & Location & Imaging & Prognosis & Reference \\
\hline 1 & $26 y / M$ & $\begin{array}{l}\text { Based on Sella pel- } \\
\text { lucidum }\end{array}$ & $\begin{array}{l}\text { CT: hypodensity with peripheral } \\
\text { calcification. } \\
\text { MRI: Mixed intensity. }\end{array}$ & $\begin{array}{l}\text { The tumor was removed entirely. } \\
\text { The patient's symptoms improved at } 6 \text { months } \\
\text { of fellow up. }\end{array}$ & $\begin{array}{l}\text { Muzumdar, } \\
\text { 2001[8] }\end{array}$ \\
\hline 2 & $14 y / M$ & $\begin{array}{l}\text { Based on the right } \\
\text { wall of cavernous } \\
\text { sinus }\end{array}$ & $\begin{array}{l}\text { CT: mixed density. } \\
\text { MRI: mixed intensity. } \\
\text { Contrast: heterogeneous internal } \\
\text { enhancement. }\end{array}$ & $\begin{array}{l}\text { The tumor was removed completely. } \\
\text { No evidence showed recurrence at the } 8 \\
\text { months of fellow-up. }\end{array}$ & $\begin{array}{l}\text { Tobias, } \\
\text { 2001[1] }\end{array}$ \\
\hline 3 & $45 y / M$ & $\begin{array}{l}\text { Based on the dura } \\
\text { mater covering cer- } \\
\text { ebellar hemisphere }\end{array}$ & $\begin{array}{l}\text { CT: mixed density with calcifications } \\
\text { in the solid portion. } \\
\text { MRI: Mixed intensity. }\end{array}$ & $\begin{array}{l}\text { The tumor was removed entirely. } \\
\text { The patient's symptoms improved at } 1 \text { year of } \\
\text { fellow up. Postoperative MR scan at } 16 \text { months } \\
\text { revealed no evidence of recurrence or progres- } \\
\text { sion of tumor from the residue. }\end{array}$ & $\begin{array}{l}\text { Zavanone, } \\
2002[11]\end{array}$ \\
\hline 4 & $47 y / F$ & $\begin{array}{l}\text { Based on the dura } \\
\text { mater covering cer- } \\
\text { ebellar hemisphere }\end{array}$ & $\begin{array}{l}\text { CT: homogeneous hypodensity. } \\
\text { T1WI: hypointensity. } \\
\text { T2WI: hyperintensity. } \\
\text { Contrast: partial enhancement in } \\
\text { capsule. }\end{array}$ & $\begin{array}{l}\text { The lesion was removed subtotally. } \\
\text { Postoperative MR scan at } 13 \text { months revealed } \\
\text { no evidence of recurrence or progression of } \\
\text { tumor from the residue. }\end{array}$ & $\begin{array}{l}\text { Park, } \\
\text { 2007[9] }\end{array}$ \\
\hline 5 & $27 y / M$ & $\begin{array}{l}\text { Confined within the } \\
\text { left wall of Cavern- } \\
\text { ous sinus }\end{array}$ & $\begin{array}{l}\text { MRI: mixed intensity. } \\
\text { Contrast: heterogeneous internal } \\
\text { enhancement and partial enhance- } \\
\text { ment in the capsule. }\end{array}$ & $\begin{array}{l}\text { The lesion was removed completely. } \\
\text { Postoperative MR scan at } 2 \text { years showed no } \\
\text { evidence of recurrence. }\end{array}$ & $\begin{array}{l}\text { Bonde, } \\
2008[15]\end{array}$ \\
\hline 6 & $37 \mathrm{y} / \mathrm{F}$ & $\begin{array}{l}\text { Confined within the } \\
\text { frontal Cerebral falx }\end{array}$ & $\begin{array}{l}\text { CT: hypodensity with peripheral } \\
\text { calcification. } \\
\text { T1WI: hypointensity. } \\
\text { T2WI: hyperintensity } \\
\text { Contrast: enhancement in the cap- } \\
\text { sule. }\end{array}$ & $\begin{array}{l}\text { The lesion was removed totally. } \\
\text { At } 3 \text { years of follow-up, neither neurological } \\
\text { deficits nor recurrence signs was found. }\end{array}$ & This case \\
\hline
\end{tabular}

\section{Discussion}

Herein, we reported a rare case of mature teratoma which was located within the frontal cerebral falx. Similar to this case, Bonde et al reported a 27-year-old male patient with a mature teratoma that was entirely within the confines of the dural layers of the lateral wall of the cavernous sinus [15]. It was unclear why mature teratoma could occur and develop within intracranial dura mater, but previously reported cases had shown that the dura mater might be the origin of extra-axial mature teratomas. For exam- 
ple, Tobias et al reported an adult patient with a mature teratoma arising from the lateral wall of cavernous sinus [1]. It was documented as well that mature teratomas arose from septum pellucidum $[8,16,17]$. Given that cerebral falx, cavernous sinus wall and septum pellucidum are histologically the same with dura mater, and teratomas are generally thought to arise from misplaced primordial germ cells [18], we speculate that the abnormal migration of primordial germ cells into the dura mater might be responsible for the occurrence of interdural mature teratomas.

Despite intracranial mature teratoma usually presented as a solitary lesion, multiple mature teratomas could occur concurrently at different sites within or outside cranium. Aoyama et al reported a patient with two intracranial mature teratomas simultaneously, one of which was in the pineal region and the other one in the fourth ventricle [19]. Additionally, postoperative fellow-up showed that new teratomas could occur at other sites within cranium after an initial one was removed. A patient was found to have a new teratoma in corpus callosum genu during his postoperative MRI fellow-up after the initial one in pineal region was removed [7]. In an eight-year-old patient with a removal history of intracranial mature teratoma, another two mature teratomas occurred separately in the chest area and in the right iliac region at six years after his intra-ventricular one was removed [20]. Thus, these cases suggest that the pathogenesis of teratomas might be associated with genetic alterations. Furthermore, experimental analysis data demonstrated that teratomas harbored genetic loss or mutation. Pećina-Slaus examined the samples from central nervous system and found the teratomas lost heterozygosity in the E-cadherin gene and had mutation in the exon 3 of the beta-catenin gene [21]. E-cadherin and beta-catenin are the components of adherens junctions, and functions collaboratively to play pivotal roles in epithelial cell behavior, tissue development, and cell contact inhibition. Their dysfunction would lead to morphological changes of the tissue and cells, enhanced cell motility and cancer growth. Therefore, we think genetic changes might be a factor leading to the interdural mature teratomas despite we did not analyze genetic alterations in this patient.

On CT imaging, mature teratomas often displayed heterogeneous densities due to containing different well-differentiated components. On MR imaging, they also had a pattern of mixed signal intensity and enhancement [1, 22]. By contrast, our teratoma showed predominant hypodensity with partial calcification in the capsule on CT imaging. MRI revealed that it had uniformed hypointensity on T1WI, hyperintensity on T2WI, and enhancement in the capsule. Besides our case, similar imaging patterns were found in other intracranial mature teratomas $[3$, 9]. For example, a giant intracranial mature teratoma in an adult male patient was reported to present hypodensity on CT and hyperintensity on T2WI [5]. Additionally, another mature teratoma in the sella of an adult male patient showed the same imaging features as ours but for its hyperintensity on T1WI [8]. Because the CT or MRI characteristics of teratomas are often dependent on the contents contained within them and postoperative histological examination revealed that our teratoma contained lots of keratin materials, we thought the imaging findings in our case was mainly due to the keratin materials.

Our case was pathologically proved to be a mature teratoma due to containing welldifferentiated components from mesoderm (bone and adipose tissue) and ectoderm (squamous epithelia). Although majority of the reported teratomas contained the tissues from three germ layers including endoderm, mesoderm, and ectoderm, they could occasionally develop from a single germ layer if they showed histologically divergent differentiation. Ijiri et al described a spinal mature teratoma in an adult patient, the components of which consisted of bone, cartilage, adipose tissue and blood vessels and all of them were from only one germ layer, the mesoderm [4]. In our patient, the histological findings revealed that it differentiated from two germ layers, mesoderm and ectoderm.

Total removal is the treatment of choice for intracranial mature teratomas. They are potentially resectable and surgically curable and the prognosis was excellent. Although our patient recovered uneventfully with no recurrence at three years of follow up, she should be monitored by MRI in the future, because the occurrence of malignant teratoma or germinoma was found in either adults or children patients at several years after total removal of a mature teratoma [16, 23-25]. It was recommended that radiotherapy and chemotherapy should be performed if teratomas contained immature tissues. Moreover, Barksdale et al thought, chemotherapy and radiation may be effective adjunctive therapies to improve the patients' survival [12]. However, the case reported by Kamoshima showed that even if two courses of ICE chemotherapy (ifosfamide, cisplatin and etoposide) were administrated, the size of mature teratoma remained stable [7].

In summary, we reported a rare case of interdural mature teratoma with rare imaging features on $\mathrm{CT}$ and MRI. Due to its being confined within the dura mater, interdural teratoma should be removed 
totally. Despite the patients usually had better prognosis, they should be followed up for a long period, because malignant tumor or new teratoma might arise inside or outside the cranium. To our best knowledge, this is the first case of intracranial mature teratoma within cerebral falx.

\section{Competing Interests}

The authors have declared that no competing interest exists.

\section{References}

1 Tobias S, Valarezo J, Meir K, Umansky F. Giant cavernous sinus teratoma: a clinical example of a rare entity-case report. Neurosurgery $2001 ; 48(6)$ : 1367-1370.

2 Arslan E, Usul H, Baykal S, Acar E, Eyüboğlu EE, Reis A. Massive congenital intracranial immature teratoma of the lateral ventricle with retro-orbital extension: A case report and review of the literature. Pediatr Neurosurg 2007;43(4): 338-342.

3 Becherer TA, Davis DG, Hodes JE, Warf BC. Intracavernous teratoma in a school-aged child. Pediatr Neurosurg 1999; 30(3):135-139.

4 Ijiri K, Hida K, Yano S, Iwasaki Y. Huge intradural ossification caused by a mature spinal teratoma: case report. Neurosurgery 2009; 64(6):E1200-1201.

5 Phadke RS, Shenoy AS, Hosangadi A, Nadkarni TD. Mature teratoma arising from the middle cranial fossa. Ann Diagn Pathol 2004; 8(1):28-31.

6 Beschorner R, Schittenhelm J, Bueltmann E, Ritz R, Meyermann R, Mittelbronn M. Mature cerebellar teratoma in adulthood. Neuropathology 2009; 29(2):176-180.

7 Kamoshima Y, Sawamura Y, Iwasaki M, Iwasaki Y, Sugiyama K. Metachronous mature teratoma in the corpus callosum occurring 12 years after a pineal germinoma. J Neurosurg 2008; 109(1):126-129.

8 Muzumdar D, Goel A, Desai K, Shenoy A. Mature teratoma arising from the sella--case report. Neurol Med Chir (Tokyo) 2001; 41(7):356-359.

9 Park KB, Park HS, Lee Jl, Suh YL. Mature Teratoma in the Cerebellar Hemisphere of an Adult. J Korean Neurosurg Soc 2007; 41(3): 180-181.

10 Nishigaya K, Ueno T, Satou E, Nukui H, Kobayashi M. Mature teratoma incidentally found in the sylvian fissure: a report of an autopsy case. Noshuyo Byori 1994;11(2):131-134.

11 Zavanone M, Alimehmeti R, Campanella R, Ram-Pini P, Locatelli M, Egidi M, Righini A, Bauer D. Cerebellar mature teratoma in adulthood. J Neurosurg Sci 2002; 46(1):35-38.

12 Barksdale EM Jr, Obokhare I. Teratomas in infants and children. Curr Opin Pediatr 2009; 21(3):344-349.

13 Urculo E, Arrazola M. Epidermoid cyst of the corpus callosum. Neurochirurgie 1992; 38(5): 304-308.

14 Bhatoe HS, Mukherji JD, Dutta V. Epidermoid tumour of the lateral ventricle. Acta Neurochir (Wien) 2006; 148(3): 339-342.

15 Bonde V, Goel A, Goel NK. Giant interdural teratoma of the cavernous sinus. J Clin Neurosci 2008;15(12):1414-1416

16 Kamiya K, Inagawa T, Ogasawara H. A case of malignant teratoma developing from the septum pellucidum 7 years after removal of a mature teratoma in the pineal region. Surg Neurol 1988; 30(6): 462-467.

17 Radek A, Karbownik J, Maciejczak A. A case of intrasellar teratoma. Neurol Neurochir Pol 1994; 28(6):939-943.

18 Smirniotopoulos JG, Chiechi MV. Teratomas, dermoids, and epidermoids of the head and neck. Radiographics 1995; 15(6):1437-1455.

19 Aoyama I, Makita Y, Nabeshima S, Motomochi M. Intracranial double teratomas. Surg Neurol 1982; 17(5):383-387.

20 Colpan ME, Unlu A, Erden E, Kanpolat Y. Multilocated mature teratoma: a case report and review of the literature. Acta Neurochir (Wien) 2004; 146(10):1145-1150.
21 Pećina-Slaus N, Niku Eva-Martić T, Beros V, Tomas D. Genetic alterations of E-cadherin and beta-catenin in germinoma and teratoma: report of two central nervous system cases. Pathol Oncol Res 2007; 13(4):370-374.

22 Osborn AG, Preece MT. Intracranial cysts: radiologic-pathologic correlation and imaging approach. Radiology 2006; 239(3): 650-664.

23 Ikeda J, Sawamura Y, Kato T, Abe H. Metachronous neurohypophyseal germinoma occurring 8 years after total resection of pineal teratoma. Surg Neurol 1998; 49(2):205-209.

24 Sugimoto K, Nakahara I, Nishikawa M. Bilateral metachronous germinoma of the basal ganglia occurring long after total removal of a mature pineal teratoma. Case report. Neurosurgery 2002; 50(3):613-617.

25 Utsuki S, Oka H, Sagiuchi T, Shimizu S, Suzuki S, Fujii K.. Malignant transformation of intracranial mature teratoma to yolk sac tumor after late relapse. J Neurosurg 2007; 106(6):1067-1069. 